\title{
PROFESSORES DA REDE MUNICIPAL DE ENSINO DE SANTA MARIA/RS: RELATO DE PROCESSO DE FORMAÇÃO CONTINUADA
}

DOI 105902/0102830817419

Data de submissão: 25/03/2015

Data de aceite: 25/05/2015

Gislaine A. R. da Silva Rossetto Universidade Federal de Santa Maria gislainesilvarossetto@gmail.com

João Francisco Magno Ribas Universidade Federal de Santa Maria ribassjfm@hotmail.com

Maria Cecília Camaro Gunther Universidade Federal de Santa Maria mceciliacg6@hotmail.com

Daiane Oliveira da Silva Universidade Federal de Santa Maria

Elciana Buffon

Universidade Federal de Santa Maria elciana_buffon@hotmail.com

Carlos Alberto Borin Junior Instituto Estadual de Educação Tiaraju, São Sepé, RS junior_borin@hotmail.com

\section{Resumo}

Esse texto relata a formação de professores realizada durante 2011 e 2012 com docentes de Educação Física cujo objetivo foi contribuir com a elaboração e o desenvolvimento de propostas relacionadas à organização do trabalho pedagógico. Os registros das formações tiveram como base vídeos, atas, avaliações individuais e coletivas realizadas no término de cada encontro. As análises sinalizam para a continuidade no processo de formação para esses professores visando a autonomia individual e coletiva. Consideramos que a continuidade da formação desloque-se para as próprias escolas, materializando sua centralidade como espaço formativo, a ser constituído organicamente como lugar de produção de conhecimento.

Palavras-chave: formação de professores, educação física escolar, formação continuada. 


\section{INTRODUÇÃO}

O presente relato aborda o processo formativo de professores realizado durante 2011 e 2012 com docentes de Educação Física da Rede Municipal de Ensino de Santa Maria/RS que teve início em 2011 junto ao Programa denominado Ações Extensionistas de Assessoramento às Escolas de Educação Básica para articulação entre Desenvolvimento Institucional Escolar e Desenvolvimento Profissional de Professores que teve o apoio do Programa de Ações Extensionistas Multidisciplinares de Formação Continuada de Professores (PROEXT). O objetivo desse programa, que envolveu as áreas das Artes Visuais, Educação Física, Filosofia, Ensino de Ciências e Matemática, foi dialogar com as Secretarias de Educação e as Escolas de Educação Básica com vistas a elaboração e desenvolvimento de propostas inovadoras sobre a organização do trabalho escolar, em especial as Práticas Pedagógicas e os Processos de Formação Continuada de Professores em Serviço. Na área da Educação Física o PROEXT foi integrado por representantes do Grupo de Pesquisa em Lazer e Formação de Professores (GPELF) ${ }^{1}$.

O Grupo de Pesquisa em Lazer e Formação de Professores (GPELF) contemplou em sua concepção de Educação Física os conhecimentos desenvolvidos no contexto Escolar que tenham como especificidade a cultura corporal de movimento expressada por meio dos jogos e esportes. Esta concepção baseia-se em Bracht (1997), quando afirma que a área da Educação Física se constitui em um saber fazer e um saber sobre o fazer corporal. Através das ações das formações, O GPELF vem constatando que o entendimento dessas novas concepções de Educação Física não tem atingido o cotidiano dos professores de Educação Física onde se observa a dificuldade de organização do trabalho pedagógico e da didática, assim como sua articulação com os referidos Projetos Pedagógicos (PPs) e referenciais curriculares da área (Estado do Rio Grande do Sul e Parâmetros Curriculares Nacionais - PCNs).

Após as avaliações das ações realizadas em 2011 o GPELF, junto com os professores da Rede Municipal de Santa Maria, decidiu continuar as ações de formação continuada em 2012. Assim, este trabalho relata e analisa o processo de formação continuada de professores de Educação Física da rede municipal de ensino de Santa Maria/RS realizado pelo grupo GPELF durante os respectivos anos.

\footnotetext{
${ }^{1}$ No decorrer do processo integrantes do Grupo Pátio passaram a participar do projeto.
} 
Esse relato está organizado em três momentos: primeiro são considerados alguns princípios sobre a formação continuada, em segundo é descrito a trajetória do programa e, por fim, são apresentados os desafios relativos ao processo de formação continuada experienciados pelo grupo que integrou o PROEXT da Educação Física.

\section{FORMAÇÃO CONTINUADA E SUAS PERSPECTIVAS}

Partindo-se do pressuposto que a formação continuada está presente em leis e diretrizes da educação nacional, este processo formativo deve ser garantido em todos os níveis de ensino, porém isso nem sempre é uma prática constante.

Considerando-se que a legislação, prevê a formação dos professores, cursos, pesquisas e pequenas intervenções universitárias, observa-seno cotidiano desses professores dificuldade em participarem de processos de formação continuada. É o caso dos professores da Rede Municipal e Estadual de Santa Maria, que mesmo quando convocados a participar, apresentam dificuldades para se afastar da escola em função de não terem com quem deixar suas turmas. O mesmo ocorre com os cursos de pósgraduação, nos quais os professores também encontram dificuldades em dedicar-se às atividades do curso devido a não liberação de seus encargos didáticos em suas instituições. Tal realidade afeta diretamente na possibilidade de se pensar na formação de professores de forma contínua de modo a possibilitar reflexões e mudanças na qualidade do trabalho pedagógico. Outro elemento influenciador desse processo são as políticas públicas, as quais na maioria dos casos são elaboradas e efetivadas a partir do discurso acadêmico, sem ouvir atentamente os docentes, fato que revela a fragilidade de comunicação e de escuta entre ambos (MOLINA NETO; MOLINA, 2002).

E, por fim, um dos fatores que contribuiriam para uma melhoria desse processo de formação é o incentivo e garantia de espaços e tempos formativos organizados e sistematizados a partir das necessidades e interesses apresentados pelos próprios professores.Salientamos, também, a importância da tomada de consciência dessas necessidades pelos docentes, pois isso é de suma importância para sua autoformação e para que a aprendizagem da sua docência aconteça (ROSSETTO; BAPTAGLIN; BOLZAN, 2012).

No entanto, o que encontramos são professores estimulados a sair da sala de aula, pela ñndústria da Formação Permanenteò para serem atualizados em questões que pouco tem a ver com as dificuldades que encontram nas escolas (MOLINA NETO, 1997). 
Isso sinaliza o quanto a formação poderá estimular ou não este profissional, afastando-o ainda mais da possibilidade de qualificar e aprofundar o seu saber docente.

Assim, o grupo tem trabalhado com alguns princípios considerados como essenciais para as ações de formação continuada de professores(MARIN e cols., 2011, p. 261-262):

\footnotetext{
-Necessidade de democratização do conhecimento historicamente acumulado em torno das políticas públicas e dos pressupostos que orientam a prática pedagógica.

-Necessidade de compreensão do movimento teórico-ideológico de luta que se expressa no contexto educacional, de maneira que possamos distinguir as ações que se apresentam como sendo defensoras dos interesses coletivos daquelas carregadas de imposições originadas pela ideologia do capital.

-A escola deve servir aos interesses populares, colocando-se contra a hegemonia burguesa e construindo a hegemonia da classe trabalhadora.

- Uma proposta de formação continuada não tem um período delimitado para sua conclusão, pois as ações desenvolvidas devem adquirir um caráter duradouro e contínuo e devem vigorar como parte do conjunto das práticas cotidianas tanto do contexto da escola, como da universidade.

-A Formação Continuada se se estabelece por meio do exercício de luta ideológica, pois as demandas sociais, na maioria das vezes, condizem com os interesses de uma privilegiada minoria.
}

Esse entendimento também considera como objetivo da formação continuada, construir um conhecimento coletivo gerado a partir das necessidades históricas e culturais, sob os aspectos das experiências de vida pessoal e profissional, e dos conhecimentos historicamente construídos, contribuindo para promover transformações nas práticas coletivas. Em meio a estes entendimentos Nóvoa (2007) reforça que a formação não se constrói por acumulação (de cursos, de conhecimentos ou de técnicas), mas sim, por meio da reflexividade crítica sobre as práticas e de (re) construção permanente de uma identidade pessoal.

\section{TRAJETÓRIA DO PROCESSO ñ DO PROEXT AO PROFEF}

O processo de formação continuada de professores de Educação Física da rede municipal de ensino de Santa Maria / RS realizado em 2011 e 2012 foi orientado pelo enfoque crítico dialético, buscando captar sua trajetória histórica, como um fenômeno social que abriga, ao mesmo tempo contradições e potencialidades de transformação (SANCHEZ GAMBOA, 2009). A base para esse relato foi a análise do processo, no qual utilizou o material de registro das atividades do programa: os vídeos dos encontros, as 
atas e as avaliações individuais e coletivas elaboradas ao término de cada encontro.

O início do processo de elaboração dos encontros de formação ocorreu no PROEXT no qual membros do Grupo de Pesquisa em Lazer e Formação de Professores (GPELF) foram convidados a integrar elaborando as contribuições específicas da área da EF. Inicialmente foram feitos encontros reunindo diferentes áreas do conhecimento, com temas mais abrangentes, igualmente aconteceu no final de 2011, quando realizou-se um encontro de avaliação e confraternização.

Em 2011, após vários momentos de organização junto a Secretaria Municipal de Educação, definimos 6 encontros, esses realizados na Escola Municipal de Aprendizagem Industrial e outros na UFSM. Nessas reuniões trabalhamos textos, filmes, dinâmicas e atividades lúdicas que geraram discussões e análises de elementos relacionados à prática pedagógica e ao conhecimento da Educação Física.

Ao longo do processo formativo os professores apresentaram objetivos, interesses e necessidades que auxiliaram na identificação de temas a serem enfatizados nos estudos. Ao final de 2011 a avaliação do processo indicou para a continuidade dos encontros, mesmo com a finalização do PROEXT. Assim, durante o ano de 2012 foram realizados encontros mensais com participação média de 20 a 25 professores. Todos os encontros de formação foram precedidos de reuniões preparatórios entre professores e estudantes do CEFD/UFSM. Importante dizer que esses momentos se constituíram em espaços de formação também para docentes e acadêmicos que dele tomaram parte ${ }^{2}$.

Ao longo de todos os encontros procurou-se assegurar um momento de avaliação, escrita ou oral, que pudesse fornecer informações relevantes para o planejamento da continuidade do processo. Constatamos que as aulas de EF fundamentadas em diferentes concepções de ensino (Desenvolvimentista, Construtivista, Crítico-emancipatória e Críticosuperadora) foram significativas para os professores da rede. Isso foi evidenciado pela participação dos professores nas atividades propostas, na observação e no registro atento dos demais que optaram não experiência-las.

Ao final de cada encontro fazíamos discussões nas quais os participantes relatavam como se sentiram durante a aula e também as relações que estabeleciam com suas próprias práticas cotidianas na escola. Esses encontros foram avaliados positivamente pelos participantes destacando a conexão entre as concepções de ensino de EF e a materialização do trabalho pedagógico no seu cotidiano.

\footnotetext{
${ }^{2}$ Para diferenciar essa etapa do processo que se desenvolveu após o término do PROEXT, passaremos a usar a sigla PROFEF representando o projeto que foi registrado no Gabinete de Projetos do CEFD/UFSM para o desenvolvimento dessas ações formativas cujo título é ñorganização do trabalho pedagógico do professor de educação física na Rede Municipal de Santa Mariaò.
} 
Nesse sentido, parece eminente trazermos as questões levantadas por Gatti (2000) a qual nos remete a formação de professores como algo desafiador para as políticas educacionais, em razão da grande expansão das redes de ensino em curto espaço de tempo e a ampliação consequente da necessidade desses docentes. Por essa razão Rossetto; Baptaglin; Bolzan (2012, p. 01) afirmam que

\begin{abstract}
A formação continuada de professores constitui-se em um processo complexo e de dimensões que ultrapassam a elaboração e execução de normativas legais, assim como investimentos de grande porte. Trazê-la para a pauta de discussão suscita que a repensemos como uma ação que leva em conta a aprendizagem docente, a qual considera as necessidades e os interesses dos sujeitos envolvidos, bem como suas condições de trabalho e de lugar para que essa formação seja possível de se concretizar.
\end{abstract}

Nessa direção, o PROFEF buscou superar aspectos bastante criticados em relação às iniciativas de caráter transmissivo e unilateral de formação continuada, buscando estabelecer uma relação dialógica com a realidade escolar e com os professores da Rede, contemplando expectativas desse grupo. Por outro lado, o PROFEF procurou assegurar os princípios teórico-metodológicos já apresentados anteriormente.

\title{
REFLEXÕES SOBRE O CAMINHO PERCORRIDO
}

As diferentes concepções de formação continuada dos professores que participaram da formação oscilaram entre expectativas voltadas a um processo de reflexão a partir da própria prática e aquisição de novos conhecimentos acerca do ensino da Educação Física. Evidenciou-se a carência por momentos de compartilhar os trabalhos realizados e construir orientações metodológicas compatíveis com a realidade na qual atuam, e aberta a inovações. No decorrer do processo foi necessário entrecruzarmos as concepções desses professores com o que idealizamos como processo de formação continuada tendo como base trocas de conhecimento entre os envolvidos.

O primeiro objetivo apresentado pelo grupo de professores para o seu próprio processo formativo foi elaborar uma sequência metodológica de conteúdos para os Anos Finais do Ensino Fundamental (AFEF). A seleção de conteúdos deveria resultar de discussões e avaliações conjuntas que possibilitassem a atribuição de sentido e também continuidade durante cada ano/série e no conjunto da escolarização. Isso remete ao entendimento de que alguns princípios precisam ser considerados no momento da 
escolha dos conteúdos da Educação Física como sua relevância social, sua contemporaneidade e adequação às possibilidades sócio-cognoscitiva do aluno (SOARESe col, 2012). Outro elemento considerado foi a necessidade de assegurar a realização das aulas de Educação Física para os AFEF por professores especialistas. Tal procedimento, segundo os professores, justifica-se pela relevância no processo de aprendizagem dos estudantes, bem como pela ampliação de atuação no campo profissional.

As formas concebidas de esporte, manifestadas pelo grupo de professores, constituem um dos elementos debatidos nas formações, sendo a competição entendida como elemento central do ensino das práticas esportivas. Nesse sentido, verificamos que os professores, por estarem a algum tempo sem debater essas questões, trouxeram consigo entendimentos marcados pela formação inicial. Segundo Soares e col. (2012) enfatizar os princípios da ludicidade e da criatividade reconsiderando o princípio do rendimento, deve ser o que os professores de Educação Física devem privilegiar. Isso é o que defendemos para a Educação Física escolar.

Quanto a compreensão inicial do grupo de professores sobre as suas perspectivas de formação continuada, constatamos um salto qualitativo no entendimento do espaço de formação. De uma formação de caráter instrumental e unilateral chegou-se a uma visão ampliada dos conhecimentos através do estudo, debates e troca de experiências, orientada por um processo de reflexão, espaço inexistente no seu cotidiano. Isso corrobora o que diz Libâneo (s/d, p.227):

[...] a formação continuada pode possibilitar a reflexividade e a mudança nas práticas docentes, ajudando os professores a tomarem a consciência das suas dificuldades, compreendendo-as e elaborando formas de enfrentá-las. De fato, não basta saber sobre as dificuldades da profissão mas refletir sobre elas e buscar soluções, mediantes a ações coletivas.

Nessa perspectiva entende-se a importância do processo de formação continuada na realidade de vida profissional desses docentes, com o sentido de estruturar espaços de trocas entre todos os envolvidos vislumbrando avanços no comprometimento individual e coletivo do fazer reflexivo.

O processo de formação aqui relatado deve ser entendido como parte de um percurso formativo onde os professores envolvidos (re) constroem conhecimentos analisados nos diferentes encontros, e os fundem com suas experiências cotidianas em um processo idiossincrático.

Ressaltamos que o processo reflexivo apresentado tem sido orientado por uma 
relação dialética entre o fazer cotidiano na escola e o pensar/discutir/teorizar coletivamente sobre ele com a mediação do grupo constituído pela equipe coordenada por professores do PROFEF. Nesse sentido compreendemos que

A experiência docente é espaço gerador e produtor de conhecimento, mas isso não é possível sem uma sistematização que passa por uma postura crítica do educador sobre suas próprias experiências. Refletir sobre os conteúdos trabalhados, as maneiras como se trabalha, a postura frente aos educandos, frente ao sistema social, político, econômico, cultural é fundamental para se chegar à produção de um saber fundado na experiência. (GHEDIN, 2002, p.135)

Os passos dados até aqui sinalizam a importância de uma continuidade no processo de formação continuada para esses professores em direção à construção da autonomia individual e coletiva desse grupo em buscar, organizar e sistematizar espaços de estudos e reflexões acerca de sua práxis pedagógica e, consequentemente, investirem em sua própria formação. É instigante pensar que a continuidade desse processo talvez passe pelo deslocamento das atividades de formação para as próprias escolas, materializando a centralidade do espaço escolar como espaço formativo, a ser constituído organicamente como lugar de produção de conhecimento.

Marques (1992, p.195) é enfático em relação a importância de que a escola seja o lócus central para a formação continuada de professores. Nas palavras do autor é

\begin{abstract}
No exercício da profissão, cumpre-se faça a formação nos seus próprios lugares e tempos, no caso do educador, o tempo-espaço mais específico da sala de aula e da escola. Este é o mundo de referências de todo processo formativo. Em todas as suas instâncias, quer nas preparatórias, quer nas que se seguem a título de formação continuada, tudo se deve organizar e conduzir em função do ensinoaprendizagem mediado pela docência e na escola.
\end{abstract}

A centralidade da escola na formação continuada propicia o fortalecimento da autonomia dos professores frente à organização do trabalho pedagógico, de modo a superar os aspectos estritamente técnicos da docência agregando também seu sentido político e orientador.

O processo de formação continuada desenvolvida com os professores de Educação Física da rede municipal de ensino de Santa Maria proporcionou a constatação e elaboração de importantes questões estruturais que condicionam o trabalho pedagógico desses docentes, os quais costumam balizar o ensino da EF.Os professores que lograram uma participação mais regular nos encontros expressaram inquietações que merecem novas formas de abordagem para esse tipo de processo formativo. E uma delas é que se 
voltem ao interior das escolas de modo a fortalecer a produção e atuação coletiva para além de práticas reflexivas isoladas e superficiais.Esse direcionamento não deve ser entendido como um isolamento das escolas mas, sim,como um fortalecimento e como uma oportunidade de diálogo entre as mesmas,para além de uma relação de subalternidade aos órgãos gestores, como executora de projetos elaborados sem a sua efetiva participação.

\section{REFERÊNCIAS BIBLIOGRÁFICAS}

BRACHT, V. Educação Física e Ciência: cenas de um casamento (in)feliz. 3. ed. ljuí: Ed. UNIJUI, 2007.

COLETIVO DE AUTORES. (2012) Metodologia de Ensino da Educação Física. São Paulo: Cortez.

GATTI, Bernadete A. Produção da pesquisa em educação no Brasil e suas implicações socio-políticoeducacionais: uma perspectiva da contemporaneidade. In: Trabalho apresentado na III Conferência de Pesquisa Sociocultural. Campinas. 2000.

GHEDIN, E. Professor reflexivo: da alienação da técnica à autonomia da crítica. In: PIMENTA, S. G. e GHEDIN, E. (Orgs.). Professor Professor reflexivo no Brasil reflexivo no Brasil: gênese e crítica de um conceito. São Paulo: Cortez, 2002. p. 129-149.

LIBÂNEO, José Carlos. Organização e gestão da escola: teoria e prática. 5 ed. São Paulo: Alternativa, s/d.

MARIN, E. C. et al. Formação Continuada em Educação Física: Relação entre Mundo do Trabalho, Políticas Educacionais e Educação. Revista Movimento, Porto Alegre/RS, v. 17, n. 2 (2011).

MARQUES, Mário Osório. A formação do profissional da educação. ljuí: UNIJUÍ, 1992.Marques, 1992.

MOLINA NETO, V. A formação profissional em educação física e esportes. Revista Brasileira de

Ciências do Esporte, v.19, n.1, p.31-44, 1997.

MOLINA, R. K., MOLINA NETO, V. O pensamento dos professores de educação física sobre a formação permanente no contexto da escola cidadã: um estudo preliminar. Revista Brasileira de Ciências do Esporte. Campinas. V. .22, p.73 - 85, 2001.

NÓVOA, Antonio. Os Professores e as Histórias da sua Vida. In: NÓVOA, A. (org). Vidas de Professores. Porto Ed., 2007.

ROSSETTO, A. R. G.; BAPTAGLIN, L.A.;BOLZAN, D.P.V. A atividade docente de estudo 
e a aprendizagem da docência: o que contam as narrativas dos professores em formação continuada. XVI ENDIPE - Encontro Nacional de Didática e Práticas de Ensino - UNICAMP - Campinas ï 2012 Junqueira \& Marin Editores - Livro 2 - p.004550.

SANCHEZ GAMBOA, S. Saberes, conhecimentos e as pedagogias das perguntas e das respostas: atualidade de antigos conflitos. Práxis Educativa, Ponta Grossa, v.4, n.1, p.9-19, jan.-jun. 2009. Disponível em <http://www.periodicos.uepg.br

\title{
TEACHERS OF MUNICIPAL SCHOOLS IN SANTA MARIA/RS: REPORT OF PROCESS OF CONTINUED EDUCATION
}

\begin{abstract}
This study reports the process of teacher formation carried out with Physical Education teachers between 2011 and 2012, aiming to contribute with the elaboration and the development of proposals related to the organization of their pedagogical work. Developed based on education records such as videos, minutes, individual and group assessments carried out at the end of every meeting. The analyses point to the continuity in the education process of these teachers aiming to their individual as well as group autonomy. We expect that the continuity of education moves to within schools, materializing its importance as a place of education to be organically built as an environment of know ledge production.
\end{abstract}

Keywords: teacher formation, school physical education, continued education.

\section{PROFESORES DE LA RED MUNICIPAL DE ENSEÑANZA DE SANTA MARIA/RS: RELATO DE PROCESO DE FORMACIÓN CONTINUADA}

\begin{abstract}
Resumen
Ese texto relata la formación de profesores realizada durante 2011 y 2012 con docentes de Educación Física cuyo objetivo fue contribuir con la elaboración y el desarrollo de propuestas relacionadas a la organización del trabajo pedagógico. Los registros de las formaciones tienen como base videos, actas, evaluaciones individuales y colectivas realizadas en el término de cada encuentro. Los análisis para la continuidad en el proceso de formación para esos profesores visando la autonomía individual y colectiva. Consideramos que la continuidad de la formación se desplace para las propias escuelas, materializando su centralidad como espacio formativo, a ser constituido orgánicamente como lugar de producción de conocimiento.
\end{abstract}

Palabras clave: formación de profesores, educación física escolar, formación continuada. 